
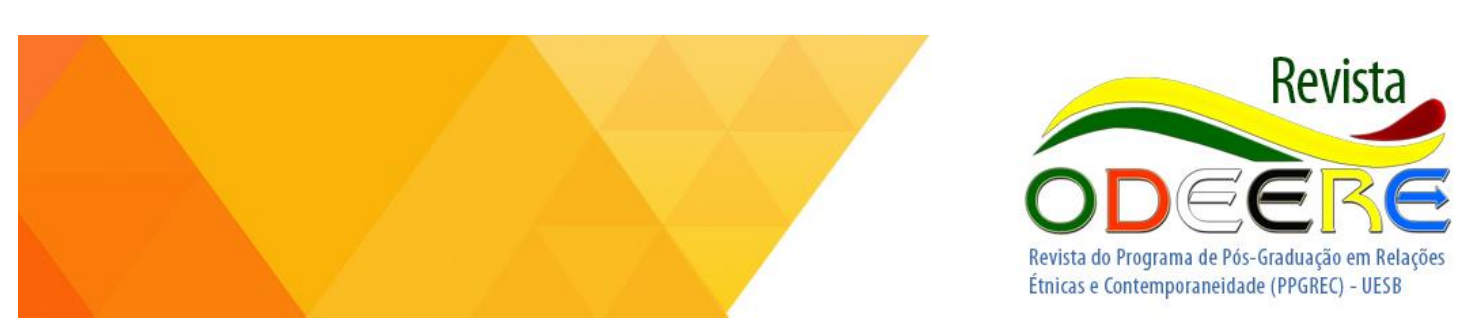

\section{Lei Áurea no Brasil, festas em Lagos (Nigéria): identidade $\mathrm{e}$ representação*}

\author{
Angela Fileno da Silva \\ Universidade de Guarulhos (UNG) \\ angelafilenos@gmail.com
}

\footnotetext{
* Este artigo é parte de minha pesquisa de doutoramento financiada pela Coordenação de Aperfeiçoamento de Pessoal de Nível Superior (CAPES), a partir do Programa de Excelência Acadêmica (PROEX).
}

Resumo: Este artigo propõe discutir as formas de representação da identidade dos brasileiros que viveram na cidade de Lagos, em 1888. A ideia é analisar as comemorações que saudaram a notícia da abolição da escravidão no Brasil. Estas festas foram realizadas por brasileiros estabelecidos em território lagosiano, duraram vários dias e ganharam as páginas de jornais como o Lagos Observer e a Government Gazette. Nestes periódicos é possível perceber que alguns dos signos de pertencimento à comunidade foram constituídos por indivíduos de fora do grupo. Estes signos de pertencimento construídos sobre os brasileiros se diferenciavam daqueles formulados pelos próprios brasileiros estabelecidos na cidade. A distinção entre as duas elaborações discursivas registradas pela imprensa lagosiana serve de suporte para pensar as variações dos sentidos de ser brasileiro em Lagos no final do século XIX.

Palavras-chave: brasileiros em Lagos, Nigéria, Lagos Observer, Government Gazette, festas da abolição.

Abstract: This article aims to discuss the forms of representation of the Brazilians identity that use to live in the city of Lagos, in 1888. The idea is to analyze the celebrations that greeted the news of the abolition of slavery in Brazil. Performed by Brazilians established in Lagosian territory, these celebrations lasted several days and won the pages of newspapers as the Lagos Observer and the Government Gazette. In these newspapers it is possible to see that some of these community belonging 
symbols were made up from outsiders. These community belonging symbols made about Brazilians differed from those made by Brazilians established in the city. The distinction between these two discursive elaborations recorded by Lagosian press support to think about the changes in the way of being Brazilian in Lagos in the late nineteenth century.

Key-words: Brazilians in Lagos, Nigeria, Lagos Observer, Government Gazette, Abolition ball.

\section{Introdução}

Lagos está localizada na extremidade oeste da principal ilha que compõe uma rede de lagoas, estuários e canais paralelos ao litoral do atual Golfo do Benim. No século XVI, a cidade se constituiu como ponto de apoio aos pescadores que viviam e transitavam na região. Na década de 1760, a ascensão do obá Akinsemoyin e a chegada do negreiro João de Oliveira à ilha modificaram seu papel no comércio atlântico de escravos. ${ }^{1} \mathrm{~A}$ instalação do novo obá e sua associação aos traficantes que operavam o comércio de cativos entre a Costa da Mina e Salvador fez de Lagos o principal embarcadouro de escravos na primeira metade do século XIX.

De acordo com a base a dados The Trans-Atlantic Slave Trade, entre 1801 e 1810, a cidade exportou 10.955 cativos para as Américas. Para termos uma ideia da representatividade deste volume de indivíduos traficados, a cidade de Ajudá - neste momento a segunda maior exportadora de escravos da Costa da Mina - encaminhou no mesmo intervalo de tempo 5.999 indivíduos à escravidão no Novo Mundo. ${ }^{2}$ O predomínio de Lagos no tráfico atlântico perdurou até 1850, ano em que a cidade se tornou protetorado da Grã-Bretanha após um intenso bombardeio realizado pelo Esquadrão Africano, formado por naus pertencentes à armada britânica.

\footnotetext{
${ }^{1}$ Cf. VERGER, Pierre. Os Libertos: sete caminhos na liberdade de escravos da Bahia no século XIX. São Paulo: Corrupio, 1992. Além de Pierre Verger, outros pesquisadores também tratam da atuação de João de Oliveira na Costa da Mina, em: GURAN, Milton. Agudás, os 'brasileiros' do Benim face à colonização francesa do Daomé, p.505 in SANTOS, Maria Emília Madeira (dir.) A África e a Instalação do Sistema Colonial (c.1885 - c.1930). III Reunião Internacional de História de África. Lisboa: Centro de Estudos de História e Cartografia Antiga, 2000; LAW, Robin; MANN, Kristin. West Africa in the Atlantic Community: the case of the Slave Coast. Willian and Mary Quarterly, 56, 2, 1999, p.317 e SILVA, Alberto da Costa e Francisco Félix de Souza, mercador de escravos. Rio de Janeiro: Nova Fronteira/ed.UERJ, pp.23,35-36 e 63. ${ }^{2}$ Cf. http://www.slavevoyages.org/tast/database/search.faces. Acesso em 25/04/2016. É possível verificar as quantidades de cativos traficados na Costa da Mina entre os anos de 1791 e 1865 em: SILVA, Angela Fileno da. Vozes de Lagos: brasileiros em tempos do império britânico. 1840 - 1900. Tese de doutorado em História Social. USP/FFLCH, São Paulo, 2016.
}

Odeere: revista do programa de pós-graduação em Relações Étnicas e Contemporaneidade - UESB. Ano 1, número 1, volume 1, Janeiro - Junho de 2016. 
A presença dos primeiros negreiros brasileiros, em geral baianos, foi responsável por atar comercialmente Lagos e Salvador. De certo modo, a existência destes traficantes atraiu um segundo grupo de indivíduos que deixou a capital provincial baiana, atravessou o Atlântico e se estabeleceu especialmente em Ajudá, Porto Novo, Badagri e Lagos. Havia neste grupo uma distinção essencial em relação àqueles brasileiros-traficantes há muito instalados nestes e em outros pontos da Costa da Mina. Os brasileiros que desembarcaram nesta porção o litoral ocidental da África eram africanos ou descendentes de africanos de primeira geração, libertos e livres.

O ano de 1835 marcou a drástica ampliação do número de partidas da capital baiana em direção à Costa da Mina. Esta ampliação pode ser verificada no aumento das emissões de passaportes destinados a africanos e descendentes. Apenas a título de comparação, em 1834, a Polícia Provincial de Salvador expediu nove passaportes a libertos que declaravam partir em direção à África. No ano seguinte a emissão deste mesmo documento saltou para 609 e, em 1836, 410 novos passaportes foram emitidos. ${ }^{3} \mathrm{~A}$ principal justificativa para o incremento significativo das emissões deste documento está associada à Revolta dos Malês, ocorrida em janeiro de 1835, e às medidas legislativas que restringiam a vida urbana de africanos e oneravam sua permanência na cidade. Refiro-me, em particular, às leis de número nove e a de número quatorze. ${ }^{4}$

Muito já foi escrito a respeito do primeiro levante urbano que eclodiu na capital baiana na madrugada do dia 25 de janeiro de 1835. O mesmo podemos dizer dos estudos que se debruçam sobre os desdobramentos da Revolta dos Malês, tais como o clima de suspeição e vigilância instaurado em Salvador e as leis promulgadas neste contexto. Embora este assunto seja essencial ao entendimento dos movimentos de partida para a Costa da Mina de africanos e descendentes, livres e libertos, não é este o ponto sobre o qual este artigo se desenvolve. O interesse aqui está

\footnotetext{
${ }^{3}$ SILVA, Angela Fileno da. Brasileiros em Lagos: identidades no contexto da colonização britânica. Anais eletrônicos do XXII Encontro Estadual de História da ANPUH/SP, Santos, 2014, p.3.

${ }^{4}$ A lei de número nove impôs uma série de limitações à vida urbana dos africanos libertos que moravam em Salvador. Entre elas estavam a obrigatoriedade do pagamento de um imposto anual, o impedimento de africanos libertos possuírem bens de raiz (ou seja, imóveis) e a exigência de uma autorização específica para o aluguel de cômodos ou casas. A lei de número quatorze substituía os cantos de trabalho por capatazias, cujos capatazes eram indicados pela Polícia Provincial e não mais escolhidos entre os trabalhadores do canto. A análise de ambas as legislações foge à proposta deste artigo. A principal obra acerca da Revolta dos malês e de seus desdobramentos continua sendo de autoria de João José Reis: Rebelião escrava no Brasil, a história do levante dos malês (1835), Edição revista e ampliada, São Paulo: Brasiliense, 2003.
}

Odeere: revista do programa de pós-graduação em Relações Étnicas e Contemporaneidade - UESB. Ano 1, número 1, volume 1, Janeiro - Junho de 2016. 
em sublinhar que o grande volume de retorno de libertos para a região, em particular para Lagos, conferiu uma nova configuração humana ao grupo de brasileiros que já vivia na cidade. ${ }^{5}$

Uma vez estabelecidos em Lagos, estes libertos vindos do Brasil constituíram sentidos de pertencimento capazes de atar seus integrantes em torno de uma identidade que se revelava pública e coletivamente em momentos específicos. $\mathrm{O}$ ano de 1888 foi uma destas ocasiões em que a identidade brasileira ganhou as ruas da cidade. Foi também neste contexto que os jornais lagosianos imprimiram seu apoio à libertação dos escravos no Brasil. A forma como os brasileiros de Lagos festejaram a promulgação da Lei Áurea e o modo como os periódicos registraram estes acontecimentos são assuntos tratados nesse artigo.

\section{A Lei Áurea festejada em Lagos}

Em julho de 1888, uma série de cartas, artigos e editoriais que saudaram o fim da escravidão no Brasil foram publicados no jornal Lagos Observer. O periódico era impresso em oficina própria, localizada na rua Bishop, nas imediações do porto da cidade. Fundado em 1882, por J. Balckall Benjamin, o jornal foi um dos primeiros a ser produzido durante um período de tempo mais alargado e com raras interrupções. Suas edições tinham quatro páginas, periodicidade quinzenal e continuaram a ser impressas até o ano de 1890.

Em 1890, o jornal foi fechado para ser reaberto em 1894. A partir daí, o Lagos Observer adotou circulação semanal, até ser extinto três anos mais tarde, em 1897. Durante cerca de onze anos de funcionamento, o periódico publicou artigos enviados por correspondentes localizados na Cidade do Cabo, Elmina, Acra, Addah, Quitta, Fernando Pó e Porto Novo. Esta estratégia expunha as suas intenções em manter os leitores informados acerca de acontecimentos fora do território lagosiano. Além disto, o Lagos Observer manteve diversos correspondentes no Reino Unido, em específico nas cidades de Londres, Manchester e Liverpool. Suas páginas eram preenchidas por

\footnotetext{
${ }^{5}$ Em extensa pesquisa no Arquivo Público do Estado da Bahia (APEBa), Luciana Brito analisa as repercussões da Revolta dos malês a partir da legislação formulada em resposta ao clima de suspeição, vigilância e controle estabelecido em Salvador, em: BRITO, Luciana da Cruz. Sob o rigor da lei: africanos e africanas na legislação baiana (1830 - 1841), Dissertação de mestrado, UNICAMP/ IFCH, 2009; BRITO, Luciana da Cruz. Sob o Rigor da Lei: Africanos e a Legislação Baiana no Século XIX. Sankofa. Revista de História da África e de Estudos da Diáspora Africana. $\mathrm{N}^{\circ} 2$, dez.2008.pp.38-57 e BRITO, Luciana da Cruz. A legalidade como estratégia: africanos que questionaram a repressão das leis baianas na primeira metade do século XIX. Revista dos Pós-graduandos em História Social da Unicamp, n.16, 2009, pp.15-28.
}

Odeere: revista do programa de pós-graduação em Relações Étnicas e Contemporaneidade - UESB. Ano 1, número 1, volume 1, Janeiro - Junho de 2016. 
editoriais, cartas, artigos de correspondentes e três colunas que tratavam de aspectos cotidianos da sociedade de Lagos: By the Way, Tit Bits e Local News.

A primeira coluna era escrita sempre em primeira pessoa e consistia em um apanhado de breves notas acerca de acontecimentos ocorridos na cidade. A segunda, Tit Bits, tecia críticas a comportamentos e a indivíduos. Por esta razão, preservava um aparente sigilo ao citar apenas as iniciais ou os primeiros nomes daqueles que eram criticados. A Local News trazia notas de falecimento, chegadas e partidas de embarcações e de indivíduos considerados importantes, além de anúncios de festas, espetáculos teatrais e corridas de cavalos ocorridas na cidade. ${ }^{6}$

No mês de outubro de 1888, cinco meses após a promulgação da Lei Áurea em maio do mesmo ano, o Lagos Observer imprimiu em suas páginas um longo artigo que tratava de um conjunto de festas e solenidades realizadas em comemoração à abolição. Segundo o periódico, a festa foi paga com os recursos apurados em uma cotização feita entre os próprios brasileiros da cidade. Era comum os jornais lagosianos publicarem listas dos participantes de cotizações e ao lado acrescentarem o valor doado à causa. Não foram poucas as relações impressas pelo Lagos Observer na ocasião dos preparativos em torno dos jubileus de ouro (em 1887) e de diamante (1897) do reinado da rainha Victoria, por exemplo. Ao divulgar os nomes dos indivíduos que dispunham de recursos suficientes para doar às comissões que organizavam estas comemorações, os periódicos lagosianos conferiam visibilidade a parcela enriquecida da população que vivia na cidade. $^{7}$

No entanto, em 1888, os doadores que tomaram parte da cotização para a realização das comemorações da abolição no Brasil não tiveram seus nomes publicados nos periódicos locais. Dito em outros termos, embora o jornal Lagos Observer reconhecesse que os organizadores tiveram de partilhar as despesas entre os integrantes da comunidade brasileira instalada na cidade, não há qualquer menção aos doadores que possibilitaram a realização das celebrações, tal como era de costume. Uma hipótese para a ausência da publicação de uma lista de cotistas está

\footnotetext{
${ }^{6}$ Atualmente, o Lagos Observer está digitalizado, seu acesso é feito pela base de dados World Newspaper Archive, seção African Collection. Esta seção oferece ainda outros títulos de periódicos que circularam na Nigéria. Estes jornais não foram selecionados em razão do tema definido para este artigo. Na esperança de estudos futuros em língua portuguesa, relaciono a seguir dos nomes dos periódicos nigerianos disponíveis nesta base de dados e seus respectivos períodos de publicação: The Lagos Weekly Record (1891 - 1906), The Lagos Standard (1907 - 1920), Nigerian Chronicle (1908-1915); Nigerian Pioneer (1914-1922) e Times of Nigeria (1914-1920).

${ }^{7}$ Uma análise aprofundada sobre os jubileus de ouro e de diamante do aniversário de reinado da rainha Victoria pode ser lida em: SAWADA, Nozomi. The educated elite and associational life in early Lagos newspapers: in search of unity for the progress of society. Tese de doutorado, Centre of West African Studies School of History and Cultures College of Arts and Law, University of Birmingham/UK, 2011, pp.235-251.
}

Odeere: revista do programa de pós-graduação em Relações Étnicas e Contemporaneidade - UESB. Ano 1, número 1, volume 1, Janeiro - Junho de 2016. 
no fato de que apenas as doações em dinheiro eram consideradas nestas relações. Contribuições em alimentos, tecidos, bebidas ou trabalho não ganhavam as páginas do periódico. Este aspecto sugere que, os brasileiros de Lagos que organizaram a festa da abolição da escravidão tenham angariado muito mais doações em bens e trabalho do que em dinheiro, o que explicaria a ausência das relações de cotistas no Lagos Observer. ${ }^{8}$

Mesmo sem sabermos exatamente os nomes daqueles participantes que cederam artigos, valores e trabalho às comemorações da abolição, o referido jornal nos informa que a festa tomou os espaços públicos de Lagos. Na porção brasileira da cidade - assim denominada em razão da maior concentração de residências e estabelecimentos comerciais pertencentes a indivíduos que diziam integrar esta comunidade - as ruas e praças foram enfeitadas por arcos embandeirados em verde e amarelo. Duas grandes tendas foram erguidas na praça Campos e na rua Campbell, esta segunda nas imediações da catedral católica. As instalações provisórias abrigaram parte das solenidades em que membros destacados da comunidade brasileira, líderes católicos e integrantes do governo colonial se pronunciaram.

Uma solenidade presidida pelo senhor Antonio Miguel d'Assumpção marcou, em 28 de setembro de 1888, o início de um conjunto de comemorações que só alcançou termo no dia 5 de outubro. De acordo com o Lagos Observer, um grande número de observadores externos à comunidade brasileira acompanhou o discurso inicial proferido por Assumpção. Como um momento de exercício público e coletivo dos sinais culturais de pertencimento ao grupo, os populares brasileiros tomaram parte das cerimônias que se seguiram ao discurso inicial de Antonio d'Assumpção. ${ }^{9}$

Neste mesmo dia, por volta da uma e meia da tarde, realizaram-se ritos religiosos nas três igrejas da cidade: na católica Holy Cross, na anglicana Saint Paul e na wesleyana situada na praça Tinubu. No templo católico, o sermão escolhido para a ocasião reforçava a atuação britânica no combate ao tráfico atlântico e a consequente abolição da escravidão no Brasil. Ao compor uma narrativa que valorizava o papel político e militar da Grã-Bretanha o pároco da catedral católica da cidade, Paul Pellet, selecionava os aspectos que julgava relevantes para constituir a ideia de que os brasileiros haviam sofrido os males da escravidão em território estrangeiro e, assim como os

\footnotetext{
${ }^{8}$ The Lagos Observer, 13 e 20 de outubro de 1888, World Newspaper Archive, African Newspapers, 1883 - 1888.

${ }^{9}$ The Lagos Observer, 13 e 20 de outubro de 1888, World Newspaper Archive, African Newspapers, $1883-1888$.
} 
hebreus, foram recompensados com a "terra prometida" se referindo, neste caso em específico, a cidade de Lagos. ${ }^{10}$

O artigo publicado pelo Lagos Observer não tecia considerações em relação à forma como os fiéis receberam a homilia escolhida para marcar o início das comemorações pela abolição da escravatura. Sabemos apenas que o rito católico se encerrou por volta das quatorze horas e trinta minutos e que, já depois do anoitecer, a festa foi retomada na praça Campos.

A etapa noturna da solenidade foi marcada pela presença do então governador de Lagos, Cornelius Alfred Moloney. Abrigado sob uma das tendas erguidas para a ocasião, Moloney acompanhou o discurso de John O. Payne, um saro que havia se casado com uma brasileira de nome Martha Bonifácia Lydia Payne, falecida há apenas cinco meses, em abril de $1888 .{ }^{11}$

John Payne fez carreira no funcionalismo público colonial e, naquele momento, ocupava o cargo de chefe de registro, um posto considerado intermediário na burocracia lagosiana. ${ }^{12}$ Dois anos antes, em 1886, Payne havia realizado uma viagem ao Rio de Janeiro. Sua visita à corte imperial do Brasil teve o propósito de manifestar publicamente o apoio de Lagos às discussões em torno da abolição da escravidão no país. Como um saro integrado à burocracia colonial britânica, Payne se mostrava uma figura compatível ao discurso de oposição à escravidão. Durante os meses em que esteve no Rio de Janeiro sua presença foi registrada por quatro jornais cariocas: Rio News, Gazeta da Tarde, O Paiz e o Diário de Notícia. ${ }^{13}$

Dois meses após sua passagem pelo Rio de Janeiro, novamente em solo lagosiano, o Lagos Observer publicou uma correspondência em que Payne narrava sua experiência em terras brasileiras. Esta mesma edição do jornal trazia também uma reprodução (traduzida para o inglês)

\footnotetext{
${ }^{10} \mathrm{O}$ artigo foi intitulado "As festividades da emancipação (negra) brasileira na colônia" - em inglês, "The Brazilian (negro) emancipation festivities in the colony" - e foi publicado em The Lagos Observer, 13 e 20 de outubro de 1888, World Newspaper Archive, African Newspapers, 1883 - 1888.

${ }^{11} \mathrm{O}$ falecimento de Martha Bonifácia Lydia Payne foi publicado pelo Lagos Observer em 12 de maio de 1888 . Um longo texto tratava de sua participação em sociedades femininas lagosianas e mencionava que em 1886 Martha havia viajado em companhia de seu marido ao Rio de Janeiro. The Lagos Observer, 12 de maio de 1888, World Newspaper Archive, African Newspapers, $1883-1888$.

${ }^{12} \mathrm{O}$ nome de John Payne aparece citado nos relatórios dos ganhos anuais do funcionalismo colonial. Estes registros permitem considerar que Payne ocupava um cargo médio na administração britânica de Lagos, como em: Blue Book, Colony of Lagos, 1897, Civil Establishment, pp.40-51.

${ }^{13}$ A trajetória de John Payne é analisada pela historiadora Nara Muniz Improta França em: FRANÇA, Nara Muniz Improta. Producing Intellectuals: Lagosian Books and Pamphlets between 1874 and 1922. Tese de doutorado. University of Sussex, Sussex/UK, 2013, pp.175 - 187 e 205-212.
}

Odeere: revista do programa de pós-graduação em Relações Étnicas e Contemporaneidade - UESB. Ano 1, número 1, volume 1, Janeiro - Junho de 2016. 
da legislação assinada pela princesa Isabel. ${ }^{14}$ Segundo Sawada, a viagem ao Brasil foi um marco em sua carreira pública. Em cartas enviadas aos jornais de Lagos e em artigos impressos por estes veículos eram frequentes as menções à conferência realizada no Rio de Janeiro. Descrito pelos periódicos lagosianos como um exemplo de sucesso da "civilização" britânica na colônia, Payne frequentemente mencionava sua experiência na Corte do Brasil como uma forma de confirmar a posição de respeitabilidade que ocupava em Lagos. ${ }^{15}$

A leitura dos exemplares do Lagos Observer revela que em quase todos os exemplares impressos nos meses de julho, agosto e outubro havia artigos e editoriais que saudavam a nova lei. Um texto escrito pelo editor e proprietário do periódico, J. Blackall Benjamin, lembrava os discursos antiescravidão proferidos por Payne durante os meses em que esteve na corte do Brasil, elogiava a abolição e terminava com uma crítica ao "incontestável despovoamento dos países do interior" provocado pelo tráfico que alimentou a escravidão do outro lado do Atlântico. ${ }^{16}$

Artigos como estes foram acompanhados por minuciosas descrições acerca das comemorações da abolição realizadas nas ruas, praças e igrejas de Lagos. Na noite do dia 28 de setembro de 1888, John Payne falou para um público composto em sua maioria por brasileiros. Seu discurso saudava a promulgação da Lei Áurea e ratificava o papel britânico no processo de extinção da escravidão no Brasil, ressaltava as consequências do comércio escravista para o continente africano e citava os políticos que, no Brasil, haviam colaborado para a promulgação da Lei Áurea. Para comprovar sua presença em uma das sessões do senado que discutiu a abolição, Payne citou os nomes dos legisladores Duarte de Azevedo, Nabuco Gonçalves Ferreira, Affonso Celso Jr. e Alfredo Correia, como aqueles que ocuparam a tribuna e se posicionaram a favor da libertação:

Hoje nos alegramos com o triunfo da justiça - tão completa foi a mudança que, em 8 de maio, o projeto do governo pela emancipação da escravidão foi lido no senado brasileiro e os espectadores irromperam em fortes aplausos - o projeto de lei encaminhado ao Comitê Especial composto por Duarte de Azevedo, Nabuco Gonçalves Ferreira, Affonso Celso Jr. e Alfredo Correia foi aprovado e, no dia 13 do mesmo mês, recebeu a confirmação régia e tornou-se lei. O primeiro-ministro João Alfredo considerou que o sentimento nacional era fortemente a favor da

\footnotetext{
${ }^{14}$ The Lagos Observer, 14 e 21 de julho de 1888, World Newspaper Archive, African Newspapers, 1883 - 1888. Embora a carta de Payne tenha sido publicada apenas em julho, o texto informava a data e o local de sua redação: "Rio de Janeiro, 15 de maio de 1888". Neste mesmo ano de 1888, John Augustus Payne mudou seu nome para John Augustus Otonba Payne, numa referência à sua origem ijebu.

${ }^{15}$ SAWADA, Nozomi. Op.cit., 2011, pp.231-235.

${ }^{16}$ The Lagos Observer, 13 e 20 de outubro de 1888, World Newspaper Archive, African Newspapers, 1883 - 1888.
}

Odeere: revista do programa de pós-graduação em Relações Étnicas e Contemporaneidade - UESB. Ano 1, número 1, volume 1, Janeiro - Junho de 2016. 
imediata abolição e que a princesa regente era calorosamente favorável a este ato de justiça cristã com os escravizados. ${ }^{17}$

Como parte das solenidades que saudavam a extinção da abolição no Brasil, o discurso proferido por Payne na praça Campos elogiava as festividades organizadas pelo comitê brasileiro de Lagos e convidava os presentes a ouvirem as palavras do governador Cornelius Alfred Moloney. O texto lido por Alfred Moloney não aparece impresso nas páginas do jornal Lagos Observer. Neste periódico há apenas uma menção à fala do governador, seguida por uma longa descrição das festividades celebradas nas ruas e salões da cidade. O discurso lido diante do numeroso público presente na praça Campos foi publicado na Government Gazette, o jornal oficial do governo colonial britânico, cujos exemplares eram impressos em Lagos. ${ }^{18}$

Em 28 de setembro de 1888, quando Alfred Moloney discursou para os brasileiros presentes na praça Campos, ele já acumulava dez anos de experiência na administração colonial britânica da cidade. Desde 1878, Moloney ocupava cargos executivos na administração colonial lagosiana. Entre 1878 e 1880, atuou como governador em exercício de Lagos. Em 1886, ano em que a Grã-Bretanha separou Lagos da administração da Costa do Ouro, foi nomeado governador efetivo, posição em que permaneceu até 1891. Durante os anos em que esteve à frente da administração colonial, sempre se posicionou a favor do que chamava de "repatriação" de africanos e descendentes libertos vindos do Brasil. Naquela ocasião em que brasileiros de Lagos comemoravam a abolição da escravatura do outro lado do Atlântico, Moloney expôs suas percepções acerca de uma parcela da população lagosiana considerada um ponto a partir do qual seria possível "desenvolver" e "civilizar" zonas mais afastadas da costa, cuja produção das "safras comerciais" de dendê, algodão e amendoim garantiriam os ganhos necessários à manutenção da colônia. $^{19}$

Um longo preâmbulo sublinhava a atuação da Grã-Bretanha primeiro em favor da extinção do tráfico atlântico e, depois, pela abolição da escravidão no Brasil. Neste primeiro trecho, Moloney se aproximava de John Payne ao considerar a Lei Áurea um desdobramento das pressões

\footnotetext{
${ }^{17}$ The Lagos Observer, 13 e 20 de outubro de 1888, World Newspaper Archive, African Newspapers, 1883 - 1888. Tradução livre da autora. Embora o excerto do documento não mencione, o nome completo do "primeiro-ministro" citado por Payne era João Alfredo Correia (ou Corrêa) de Oliveira, cujas funções no governo imperial incluíram a de conselheiro do Império, senador, ministro e chefe do gabinete imperial.

${ }^{18}$ Government Gazette, Colony of Lagos, National Archives/UK. CO 150.2, 30 de novembro de 1888, pp.525-527.

${ }^{19} \mathrm{O}$ termo "safras comerciais" e os produtos destinados à exportação foram indicados por Martin H.Y.Kaniki em: A economia colonial: as antigas zonas britânicas in BOAHEN, Albert Adu (ed.). História Geral da África, VII: África sob dominação colonial, 1880-1935. Brasília: UNESCO, 2010. p.448.
}

Odeere: revista do programa de pós-graduação em Relações Étnicas e Contemporaneidade - UESB. Ano 1, número 1, volume 1, Janeiro - Junho de 2016. 
britânicas sobre o governo do Brasil. Esta formulação the permitiu elaborar uma argumentação que associava os ganhos do Brasil com o comércio exterior de tabaco, café, algodão, açúcar e milho, ao emprego de uma mão de obra "industriosa" nascida em território iorubá, mas "treinada" nas lavouras exportadoras do Brasil. A percepção de que o tráfico havia despovoado o interior do território que naquele momento compreendia o protetorado britânico, contribuiu para a formulação da ideia de que era desejável a instalação dos "repatriados" vindos do Brasil em áreas distantes do litoral, cuja presença britânica se fazia necessária para justificar a manutenção dos territórios sob seus domínios. ${ }^{20}$

Como suporte à sua argumentação em favor da instalação destes "repatriados", o governador anunciava ser conhecido o "forte desejo" de senhores e do governo brasileiro "de repatriar escravos não nascidos no Brasil”. Para tanto, sugeria que as associações de alforria existentes no Brasil, cuja função consistia em promover a compra da liberdade, amparassem africanos e seus descendentes em seu retorno ao seu "país nativo". ${ }^{21}$ Neste trecho, o documento resumia a função destas organizações como se fossem destinadas apenas a conceder empréstimos para compra da liberdade.

No entanto as juntas de alforria, como eram popularmente conhecidas no Brasil, poderiam cumprir funções muito mais amplas. Se associadas às irmandades religiosas, por exemplo, os valores angariados também serviam para o pagamento de enterros, socorro dos membros desvalidos ou promoção de festas e celebrações. Sobre este aspecto, ao constituir um discurso em prol da transferência de libertos do Brasil para Lagos, Moloney enfatizava os elementos considerados pertinentes ao seu posicionamento, deixando de lado as outras funções assumidas por estas organizações. ${ }^{22}$

\footnotetext{
${ }^{20}$ Este aspecto estava diretamente relacionado às determinações propostas na Ata Geral da Conferência de Berlim (1885). O sexto capítulo deste documento se referia à ocupação territorial efetiva como pressuposto ao reconhecimento do domínio colonial. A intenção de Alfred Moloney em estabelecer agricultores vindos do Brasil nas áreas do protetorado britânico era uma resposta a uma demanda política específica de disputa europeia por territórios cada vez mais distantes do litoral africano. Cf. HERNANDEZ, Leila Maria Gonçalves Leite. A África na sala de aula: visita à história contemporânea. 3a ed., São Paulo: Selo Negro, 2010, p.62-64.

${ }^{21}$ Government Gazette, Colony of Lagos, National Archives/UK. CO 150.2, 30 de novembro de 1888, pp.525-526.

${ }^{22}$ Antonia Aparecida Quintão produziu um importante estudo acerca das irmandades de homens pretos e pardos existentes em Pernambuco e no Rio de Janeiro, no século XVIII, cuja referência é: QUINTÃO, Antonia Aparecida. Lá vem meu parente: as irmandades de pretos e pardos no Rio de Janeiro e em Pernambuco (Século XVIII). São Paulo: Annablume/Fapesp, 2002. Sobre o funcionamento das irmandades, a forma como estas sociedades leigas constituíam seus bens e as comemorações praticadas por estes grupos, veja também: SOUZA, Marina de Mello e. Reis Negros no Brasil escravista: história da festa de coroação do Rei Congo. Belo Horinzo: Ed. UFMG, 2002.
}

Odeere: revista do programa de pós-graduação em Relações Étnicas e Contemporaneidade - UESB. Ano 1, número 1, volume 1, Janeiro - Junho de 2016. 
Representados como a uma comunidade "respeitável", cujos integrantes se mostravam "louváveis exemplos de cidadãos", os brasileiros que porventura desembarcariam em Lagos não poderiam chegar em melhor momento. Afinal, era desejável que os repatriados vindos do Brasil fossem "agricultores treinados" e, por este motivo, as travessias destes indivíduos deveriam ser "encorajadas" pelo governo colonial lagosiano. Como mostra da boa receptividade da administração britânica, Alfred Moloney lembrava que havia na cidade um bairro brasileiro. Além disto, ruas como a "Pedro Street" e a "Martin Street" assinalavam a importância de alguns dos brasileiros mais enriquecidos.

Para o governador de Lagos, a Lei Áurea proporcionaria o acréscimo de novos indivíduos à comunidade já existente na cidade. Vistos como agentes promotores de práticas agrícolas voltadas à exportação e difusores da civilização, Moloney justificava seu apoio ao desembarque de novas levas de "repatriados":

Os repatriados que já estão entre nós são disciplinados, industriosos, estabelecidos, desfrutam do mais elevado respeito da comunidade e, em geral, se apresentam como louváveis exemplos de cidadãos. (...) Novamente, estes repatriados têm representado, e irão representar, admiráveis centros de difusão das luzes e da agricultura entre os seus conterrâneos menos desenvolvidos. ${ }^{23}$

A ideia de que os brasileiros que viviam em Lagos haviam sido, na verdade, "repatriados" permeou a homilia do padre Paul Pellet e o discurso do governador Moloney. Embora de maneiras diferentes, ambos consideravam o desembarque de libertos vindos do Brasil como uma espécie de "retorno redentor", à semelhança da noção proposta por Abdelmalek Sayad. Para o sociólogo argelino, populações diasporizadas, cujos integrantes voltavam aos territórios de origem, seriam incapazes de retomar o lugar social deixado no momento da partida. Isto porque o retorno ao ponto de partida não permitiria o retrocesso do indivíduo ao "tempo de partida", ou seja, "tornarse novamente aquele que se era nesse momento, nem reencontrar na mesma situação os lugares e os homens que se deixou, tal qual se os deixou." 24

As interpretações de Sayad permitem perceber que o retorno de africanos libertos seria redentor porque viria após a passagem pela escravidão no Brasil. Para europeus como Pellet e Moloney, a escravidão se converteria em aprendizado, pois o apreço ao trabalho seria

\footnotetext{
${ }^{23}$ Government Gazette, Colony of Lagos, National Archives/UK. CO 150.2, 30 de novembro de 1888.

${ }^{24}$ SAYAD, Abdelmalek. O retorno, elemento constitutivo da condição de imigrante. Travessia. Revista do Migrante. Número Especial. Janeiro de 2000, p.12.
}

Odeere: revista do programa de pós-graduação em Relações Étnicas e Contemporaneidade - UESB. Ano 1, número 1, volume 1, Janeiro - Junho de 2016. 
internalizado e mantido mesmo depois da libertação. Ao sustentar uma dimensão positiva da escravidão, Pellet e Moloney expunham a ideia de que os movimentos de travessia atlântica de africanos vindos do Brasil se constituíram como um "retorno redentor" após um período de exílio que não era visto como negativo em sua essência. Esta percepção era marcada pela ideia de que os libertos que desembarcaram em Lagos trouxeram consigo um conjunto de habilidades, conhecimentos e vivências específicas. Para o padre Pellet e o governador Moloney, a experiência da escravidão no Brasil havia conferido àqueles que retornavam um verniz de civilização que os colocava num patamar distinto dos demais africanos. Esta foi uma das formas de representação produzida sobre os brasileiros por indivíduos externos à comunidade. ${ }^{25}$

\section{A festa à brasileira e autorrepresentação}

No entanto, neste caso em particular, o emblema da civilização não foi o escolhido para compor o conjunto de signos de pertencimento elaborados pelos próprios brasileiros. No dia 28 de setembro, ao cair da noite, integrantes do comitê cerimonial, autoridades britânicas e chefias locais se reuniram no Glover Memorial Hall em um jantar restrito à maioria da população existente na cidade. Apenas os integrantes mais enriquecidos da comunidade brasileira tiveram acesso a esta parte das comemorações. Este episódio em específico se mostra interessante por tornar visíveis as clivagens sociais e econômicas existentes entre os próprios brasileiros. Dito em outros termos, a separação dos programas público e privado da festa expunha a heterogeneidade da composição econômica da comunidade brasileira que, ao final da década de 1880, vivia em Lagos.

Para além desta ocasião de evidente exclusão da maioria dos brasileiros da cidade, as demais celebrações em torno da abolição contaram com uma parcela numerosa da comunidade. Como a maioria das grandes comemorações, as festividades se estenderam por vários dias. Nos dias seguintes o programa incluiu uma queima de fogos, uma sessão teatral organizada pela companhia formada por alunos da escola católica e um desfile de carnaval. A maioria destas comemorações foi realizada em espaços públicos da cidade. Mesmo quando os alunos da missão

\footnotetext{
${ }^{25}$ A ideia de que a experiência da escravidão nas Américas guardava uma função didática, na medida em que era capaz de "educar" os africanos para o trabalho aparece também nos escritos deixados pelo cônsul britânico Richard Francis Burton. BURTON, Richard Francis. A mission to Gelele, king of Dahome. 2a ed. Vol. II. London: Tinsley Brothers, 1864, p.204.
}

Odeere: revista do programa de pós-graduação em Relações Étnicas e Contemporaneidade - UESB. Ano 1, número 1, volume 1, Janeiro - Junho de 2016. 
católica se exibiram no auditório da escola, não foi imposto nenhum limite ao acesso de populares. Na etapa que contou com um desfile de carnaval, as ruas e praças foram tomadas por brasileiros que expuseram os signos de pertencimento à comunidade.

$\mathrm{Na}$ ocasião as "Brazilian Caretas", para usar aqui um termo empregado pelo Lagos Observer, ganharam as ruas em um desfile identificado pelo periódico como uma "procissão de carnaval". Neste momento um dos diversos sentidos de ser brasileiro foi pública e coletivamente ativado. Pelo menos naquelas circunstâncias, ser brasileiro não estava associado a ser civilizado, tal como os discursos reproduzidos pelos jornais faziam questão de sublinhar. O pertencimento à comunidade estava na forma como a parte popular das comemorações em torno da Lei Áurea foi arranjada.

Ao saírem às ruas entoando canções em língua portuguesa, acompanhadas por instrumentos de sopro e de percussão, os brasileiros mascarados expuseram os emblemas de um pertencimento cujas formas de exercício eram múltiplas. A língua portuguesa, o catolicismo, a musicalidade própria, o uso de máscaras e as vestimentas escolhidas para a ocasião são apenas alguns dos indícios de um pertencimento captado no instante em que os festejos populares pela abolição tomaram Lagos. É nos interstícios dos textos até aqui apresentados que podemos perceber os sentidos de ser brasileiro em Lagos no final do século XIX.

Nestes interstícios a argumentação que associa os brasileiros à civilização e ao progresso comercial da colônia britânica perde força. Nas longas descrições impressas nos periódicos analisados podemos entrever os elementos selecionados pelos brasileiros para compor os emblemas de identificação do grupo. Ainda que consideremos que certamente estes emblemas foram selecionados para integrar as celebrações, não há como descartar o fato de que a opção por estes (e não outros) é um indicativo da forma como os brasileiros representavam a si mesmos.

Além dos aspectos apontados, os textos impressos nestes jornais não se referiam aos momentos anteriores às comemorações em questão. Pouco se sabe acerca dos ensaios, encontros e discussões que prepararam a apresentação teatral elaborada pelos alunos da escola missionária católica. Pode-se dizer o mesmo dos arranjos que antecederam o desfile das "Brazilian Caretas" que tomou as ruas da cidade. A despeito das limitações impostas pelas fontes, é possível inferir que era nos momentos de preparação destas performances públicas que os sentidos de ser brasileiro se refaziam e ganhavam diferentes significados. Dito em outros termos, era nas ocasiões que antecediam ao espetáculo, quando os integrantes do grupo se encontravam para 
compartilhar seu fazer artístico, que as ideias eram postas em discussão e a língua portuguesa, por exemplo, era exercitada.

Nestas situações, os signos de pertencimento que atavam os indivíduos em torno de uma identidade comum se reelaboravam. Quando o espetáculo teatral dos alunos da missão católica chegou ao público foram estes signos que subiram ao palco. Como uma metáfora da própria comunidade brasileira de Lagos, os grupos teatrais se configuravam como espaços de discussão de ideias, participação artística e atualização dos diferentes sentidos de uma identidade brasileira que se ressignificava em resposta aos contextos em que estava inscrita.

\section{Considerações Finais}

Em Lagos, as comemorações em torno da abolição da escravidão no Brasil foram finalizadas por um baile à fantasia realizado no ainda inacabado edifício do Glover Memorial Hall. A edificação consistia em um conjunto de salas de reuniões e um auditório planejado para abrigar conferências, palestras, bailes e espetáculos promovidos por associações políticas, literárias e dramáticas. Sua construção foi uma resposta às objeções de algumas igrejas ao uso de seu espaço para a prática de atividades seculares. Batizado em homenagem ao governador de Lagos, John Hawley Glover (falecido em 1885), cujo período de atuação na administração colonial se estendeu de 1863 até 1872, a construção do Glover Memorial Hall demorou mais de dez anos para ser concluída, em $1899 .^{26}$

Em outubro de 1888, o baile à fantasia que encerrou as festas que comemoraram a promulgação da Lei Áurea não contou com a participação dos populares que integraram as outras celebrações que se espalharam pelas ruas da cidade. Tal como no jantar que marcou o início das cerimônias e que era reservado apenas aos brasileiros ricos, às autoridades britânicas e às chefias locais, o baile de encerramento restringiu seus partícipes segundo os mesmos critérios. Em outras palavras, esta etapa final da festa era vedada às camadas mais pobres da comunidade brasileira de Lagos.

Ao publicar um programa de festejos em que havia limites à participação popular, o Lagos Observer expunha parte dos processos que ajudaram a compor um conjunto de representações a

\footnotetext{
${ }^{26}$ Por quase dez anos, entre 1863 e 1872, Glover e Freeman se sucederam no governo de Lagos. Cf. MANN, Kristin. Op.cit., 2007, pp.106 e 116. Em 1887, na ocasião das solenidades que marcaram o jubileu de ouro do reinado da rainha Victoria, o governador Moloney inaugurou a pedra fundamental do Glover Memorial Hall. Na década de 1960, o edifício foi demolido e, em seu lugar, foi construído outro que serviria aos mesmos propósitos. Cf. SAWADA, Nozomi. Op.cit., 2011, p.147.
}

Odeere: revista do programa de pós-graduação em Relações Étnicas e Contemporaneidade - UESB. Ano 1, número 1, volume 1, Janeiro - Junho de 2016. 
respeito de uma identidade brasileira formulada a partir de vários enunciadores. Neste sentido, o discurso formulado sobre os brasileiros se distinguia das formas de representação constituídas pelos brasileiros.

Dentro do grupo daqueles que elaboraram representações sobre os brasileiros estavam o padre Paul Pellet, o governador Alfred Moloney e o saro John Payne. Conforme apontei ao longo deste artigo, à sua maneira, cada um destes indivíduos associava os brasileiros à ideia de civilização e de progresso material. Enfatizo ainda que a percepção de que os brasileiros se distinguiam das demais populações instaladas em Lagos decorria da passagem destes indivíduos pela escravidão no Brasil. Esta maneira de representação elaborada sobre os brasileiros silenciava acerca das assimetrias sociais, políticas e econômicas existentes na própria comunidade. Este aspecto em particular contribuiu para a constituição da ideia de que o tecido conjuntivo responsável por atar os brasileiros uns aos outros era uma identidade comum e, de certo modo, estática.

Contudo, as identidades brasileiras foram múltiplas, variáveis e, sobretudo, fluidas. Construídas a partir de um conjunto móvel e diversificado de signos de pertencimento - ou como chamou Manuela Carneiro da Cunha, de "sinais diacríticos" - os brasileiros ativaram pública e coletivamente alguns de seus sentidos de pertencimento durante as comemorações populares em torno da abolição da escravidão no Brasil. $^{27}$

Ao selecionar os elementos que seriam expostos no desfile de carnaval pelas ruas da cidade e na apresentação teatral executada pelos alunos da escola missionária católica, estes indivíduos atualizavam o que significava ser brasileiro na Lagos oitocentista. Este processo de seleção e ressignificação dos emblemas que traduziam o pertencimento ao grupo se mostrava mais evidente nas etapas públicas das comemorações.

Nestas ocasiões, brasileiros pobres e ricos desfilaram pelas ruas centrais da cidade. Vestindo suas máscaras, portando estandartes de devoções católicas e entoando canções em língua portuguesa, estes indivíduos formularam seu próprio discurso acerca de uma identidade plural e móvel. Todavia, as comemorações pela abolição não se resumiram a estes acontecimentos públicos. Tal como o Lagos Observer se preocupou em distinguir, o banquete de abertura e o baile à fantasia realizado no encerramento foram reservados apenas aos convidados,

\footnotetext{
${ }^{27}$ CUNHA, Manuela Carneiro da. Negros, estrangeiros. Os escravos libertos e sua volta à África. 2a ed. revisada e ampliada. São Paulo: Companhia das Letras, 2012, p. 242.
} 
ou seja, aos brasileiros ricos, aos britânicos que integravam a administração colonial e aos chefes locais.

Ao conferir visibilidade à parcela economicamente privilegiada destes indivíduos, o periódico lagosiano ajudava a sustentar um conjunto de representações sobre os brasileiros que, com o tempo, se tornaram associadas à totalidade da comunidade existente na cidade. Neste artigo procurei analisar como os discursos sobre os brasileiros se constituíram em resposta a interesses específicos e historicamente localizados. Se por um lado, estas formulações escamoteavam as heterogeneidades da comunidade sob o emblema da "civilização", por outro, em determinados momentos estas formas de representação se combinavam a discursos elaborados pelos brasileiros. Nesta chave, as festas constituem uma ocasião privilegiada para captar as pistas de uma identidade fluida construída por uma comunidade brasileira que, em determinados momentos, teve seus signos de pertencimento somados às elaborações discursivas formuladas pelos indivíduos externos a ela.

\section{Referências bibliográficas.}

BOAHEN, Albert Adu (ed.). História Geral da África, VII: África sob dominação colonial, 1880-1935. Brasília: UNESCO, 2010.

BRITO, Luciana da Cruz. Sob o Rigor da Lei: Africanos e a Legislação Baiana no Século XIX. Sankofa. Revista de História da África e de Estudos da Diáspora Africana. $\mathrm{N}^{\circ} 2$ 2, dez.2008.pp.38-57 . Sob o rigor da lei: africanos e africanas na legislação baiana (1830 - 1841), Dissertação de mestrado, IFCH/UNICAMP, 2009.

; A legalidade como estratégia: africanos que questionaram a repressão das leis baianas na primeira metade do século XIX. Revista dos Pós-graduandos em História Social da Unicamp, n.16, 2009, pp.15-28.

BURTON, Richard Francis. A mission to Gelele, king of Dahome. 2a ed. Vol. II. London: Tinsley Brothers, 1864.

CUNHA, Manuela Carneiro da. Negros, estrangeiros. Os escravos libertos e sua volta à África. 2a ed. revisada e ampliada. São Paulo: Companhia das Letras, 2012.

FRANÇA, Nara Muniz Improta. Producing Intellectuals: Lagosian Books and Pamphlets between 1874 and 1922. Tese de doutorado, University of Sussex, Sussex/UK, 2013.

Odeere: revista do programa de pós-graduação em Relações Étnicas e Contemporaneidade - UESB. Ano 1, número 1, volume 1, Janeiro - Junho de 2016. 
GOVERNMENT Gazettes, Colonial Office (CO), 150/2, 1887 a 1888, The National Archives, Londres.

HERNANDEZ, Leila Maria Gonçalves Leite. A África na sala de aula: visita à história contemporânea. 3a ed., São Paulo: Selo Negro, 2010.

LAGOS Observer, 1882 a 1888, World Newspaper Archive: African Collection.

LAW, Robin; MANN, Kristin. West Africa in the Atlantic Community: the case of the Slave Coast. In Willian and Mary Quarterly, 56, 2, 1999.

QUINTÃO, Antonia Aparecida. Lá vem meu parente: as irmandades de pretos e pardos no Rio de Janeiro e em Pernambuco (Século XVIII). São Paulo: Annablume/Fapesp, 2002.

REIS, João José. Rebelião escrava no Brasil, a história do levante dos malês (1835), Edição revista e ampliada, São Paulo: Brasiliense, 2003.

SANTOS, Maria Emília Madeira (dir.) A África e a Instalação do Sistema Colonial (c.1885 - c.1930). III Reunião Internacional de História de África. Lisboa: Centro de Estudos de História e Cartografia Antiga, 2000.

SAYAD, Abdelmalek. O retorno, elemento constitutivo da condição de imigrante. Travessia. Revista do Migrante. Número Especial. Janeiro de 2000.

SAWADA, Nozomi. The educated elite and associational life in early Lagos newspapers: in search of unity for the progress of society. Tese de doutorado, Centre of West African Studies School of History and Cultures College of Arts and Law / University of Birmingham/UK, 2011.

SILVA, Alberto da Costa e Francisco Félix de Souza, mercador de escravos. Rio de Janeiro: Nova Fronteira/ed.UERJ, 2004.

SILVA, Angela Fileno da. Brasileiros em Lagos: identidades no contexto da colonização britânica. Anais eletrônicos do XXII Encontro Estadual de História da ANPUH/SP, Santos, 2014.

SILVA, Angela Fileno da. Vozes de Lagos: brasileiros em tempos do império britânico. 1840 - 1900. Tese de doutorado. USP/FFLCH, São Paulo, 2016.

SOUZA, Marina de Mello e. Reis Negros no Brasil escravista: história da festa de coroação do Rei Congo. Belo Horinzo: Ed. UFMG, 2002.

VERGER, Pierre. Os Libertos: sete caminhos na liberdade de escravos da Bahia no século XIX. São Paulo: Corrupio, 1992. 
Angela Fileno da Silva: Doutora em História Social pela Universidade de São Paulo, mestre pela mesma universidade e especialista em Turismo Cultural pelo Centro Universitário Unibero. Possui graduação em História pela Universidade de São Paulo e graduação em Turismo pelo Centro Universitário Unibero. É professora da Universidade Guarulhos desde 2003. Tem experiência nas áreas de Turismo e História. Atualmente desenvolve pesquisa acadêmica sobre os seguintes temas: comunidade brasileira na África, Festa do Senhor do Bonfim na África e História Atlântica.

Artigo recebido para publicação em: Maio de 2016.

Artigo aprovado para publicação em: Junho de 2016.

Odeere: revista do programa de pós-graduação em Relações Étnicas e Contemporaneidade - UESB. Ano 1, número 1, volume 1, Janeiro - Junho de 2016. 